\title{
Effectiveness of Monetary Policy: Application of Modified Peter and Clark (PC) Algorithm under Graph-Theoretic Approach
}

\author{
Rizwan Fazal*, Md Shabbir Alam ${ }^{* *}$ iD, Umar Hayat***, Naushad Alam
}

\begin{abstract}
It is common practice that central banks around the world must adopt an inflation targeting framework; based on the assumption that inflation could be reduced by increasing interest rates. This study is first of its kind where we have developed modified Peter and Clark (PC) algorithm to determine the causal nexus between monetary policy and inflation. The results show that, causality is running from interest rate towards inflation; suggesting a positive and significant long-run relationship of interest rate with inflation in case of Pakistan. The results show that, causality is running from interest rate towards inflation; suggesting a positive association of interest rate with inflation in case of Pakistan. Furthermore, both energy prices and monetary policy have cost-side effects on inflation; however, the later becomes counterproductive whenever high interest rate is used to decrease energy push inflation. Hence, there is need of serious rethinking about current monetary policy regime.
\end{abstract}

Keywords: monetary policy; inflation; causality; Graph theory.

JEL classification: E4; E5; E42; E52.

\section{INTRODUCTION}

Monetary policy today is synonymous of interest rate policy and the central banks are using interest rate as a tool to control inflation (Kumar et al., 2020). Most of the scientific literature pertaining to inflation is based on determining causality between monetary policy or/ interest rate and inflation rate. However, how do interest rate effect inflation, the theoretical literature and empirical evidences differ remarkably. Many empirical evidences are showing that increasing interest rate adds to inflation, owing to the cost side channels of

* Pakistan Institute of Development Economics (PIDE), Quaid-e-Azam University, Pakistan; e-mail: fazal.rizwan@yahoo.com (corresponding author).

Department of Economics \& Finance, College of Business Administration, University of Bahrain, Zallaq, Bahrain; e-mail: shabbir.alam28@gmail.com.

**** Department of Economics and Development Studies, University of Swat, Pakistan; e-mail: umarhayat@ uswat.edu.pk.

$\$$ Department of Finance and Economics, College of Commerce and Business Administration, Dhofar University, Oman; e-mail:nalam@du.edu.com. 
monetary transmission mechanism (Rehman, 2015). Gibson (1923) found strong evidence in support of the idea conceived by Tooke and found a positive association between the interest rate and inflation in the UK for 200 years. This finding was referred by Keynes as 'One of the most facts in the field of Quantitative economics. Many other popular studies, Sims (1992), Barth and Ramey (2001) and Rehman (2015) among others, are favoring the existence of cost side effects of monetary policy. The theoretical literature informs that there are many causal channels through which interest rates can affect inflation. All these channels have theoretical support, but which one of these is dominant, there is still no consensus. These channels can be categorized into two streams: the demand side and the cost side channels. The cost side channels generally predict that a rise in interest rate adds to inflation; while the demand side channel generally agrees that increase in interest rate decrease inflation (Angelina and Nugraha, 2020). The existence of cost channel has very serious implications, as it suggests the conventional monetary policy to be counterproductive. Therefore, given the growing literature on cost side effects of monetary policy, these effects must be at least part of monetary policy modeling. However, the econometric models used by central banks rarely pay any attention to the cost side effects. Assuming the demand side effects only, the central banks have designed monetary policy principles such as McCallum (1981) and Taylor (1995) rules. These rules predict that increasing interest rates can reduce inflation, therefore tight monetary policy has become the most often used anti-inflation measure. However, much empirical evidences contradict this assumption and many authors have found that an increase in interest rate leads to an increase in inflation. These evidences include the findings of Sims (1992), who secured the Nobel Prize in Economics for the year 2011.

As discussed, there are many causal paths connecting interest rate and inflation; however, most of the existing studies focus only on a single equation ignoring other parallel channels. This means the methodology is ill-posed. Hence, if multiple paths are connecting the monetary policy action to its objectives, a reasonable model should take all these channels into account to get a bias-free estimate of the relation. Most of the researchers Ma et al. (2020), Rashid and Husain (2013), Osterholm and Berger (2008), Hu and Quan (2005) used Granger type causality tests to determine the causal nexus between economic variables i.e. inflation and interest rate. However, Granger type causality tests are based on single equation and checks causal inferences between two variables, and there may also be a chance that the third variable causes both variables A and B. Granger type causality does not take account of this because causality analysis shall not only rely on the temporal ordering, but must contain its roots in the structural relationship behind the causal ordering. Eventually, an alternate approach having its basis in the structural equations called Graph Theoretic Approach (GTA) which is based on Peter and Clark (PC) algorithm has overcome the above-mentioned limitations and has the ability to take into account all the theoretical channels simultaneously.

The PC algorithm of GTA were generally not conceived with time series data, because of non-stationarity in time series. To make this approach applicable, Swanson and Granger (1997) used vector autoregressive (VAR) residuals in the PC algorithm; treated them as original variables to determine causality (Hoover, 2005, 2020; Demiralp and Hoover, 2003). However, the weak point attached to VAR model residuals is that, it carries only contemporaneous information about the cross variable effect and remove past information; thus causality results cannot be fully relied. This study is therefore set out to propose a new methodology that has overcome the above-mentioned limitations and has successfully determined the causal nexus between monetary policy and inflation exampling Pakistan. The 
importance and originality of this study lie in the fact that it has explored the monetary policy effectiveness for the first time using the newly developed modified PC algorithm under the framework of GTA based on Rehman and Malik (2014) modified R residuals. The research findings will make a significant contribution to the field of monetary policy literature. Similarly, methodologically speaking, the modified PC algorithm is equally important in econometrics as a standalone method that can be applied in other areas of research.

The rest of this study is organized as follows: Section 2 discussed the monetary policy review and summarizes the causal paths that link monetary policy actions to their targets. In Section 3 detailed methodology about the novelty of modified PC algorithm is discussed. Section 4 discusses the results of modified PC algorithm and the autoregressive distributed lag model (ARDL). Finally, in Section 5 conclusions and recommendations for the researchers are stated.

\section{MONETARY TRANSMISSION CHANNELS}

This section summarizes the causal paths that link monetary policy actions to their targets. As stated earlier, the theoretical literature confirms there are many monetary transmission channels that connect monetary policy actions to their targets (Taylor, 1995).

In contemporary monetary decision-making, two rules are used most frequently, i.e. (i) Taylor rule and (ii) McCullum. Both are based on assumptions of the demand side channel. This is in fact an assumption that has been challenged by all those who find evidence of cost side effects. However, the studies on the demand side and cost side channels are both questionable, because they do not consider the complex causal mechanism involving all possible channels. A better strategy to study the effects of monetary policy would be to reflect all possible channels and causal paths. It subsequently becomes important to list all popular theoretical channels and discuss their chain of causality. All these causal paths can be tested using modified PC algorithm of GTA to establish which theory and/or channel is supported by data. This section lists the monetary transmission channels and the causal paths underlying them. It is also important to mention that most of the channels listed in the literature start with a change in money supply followed by a change in an interest rate, and then ending at inflation because historically money supply was used as a tool of monetary policy. After the general acceptability of the inflation targeting regime, the interest rate serves as the primary tool of monetary policy. In this study, we discuss each channel where the interest rate is taken as the starting point instead of money supply. Furthermore, we assume that an increase in interest rate is equivalent to reducing the money supply and vice versa.

\subsection{Interest rate Channel}

The interest rate channel is the key MTM channel in the basic investment-savings (IS) and loanable funds market ${ }^{1}$-LM (IS-LM) model. The Keynesian IS-LM MTM states that an increase in real interest rate leads to a fall in investment expenditure and aggregate demand. This in turn finally affect prices in a downward direction.

$$
\mathbf{i} \uparrow \rightarrow \mathbf{i}_{\mathbf{r}} \uparrow \rightarrow \mathbf{I} \downarrow \rightarrow \mathbf{Y} \downarrow \rightarrow \mathbf{P} \downarrow
$$


This increase in real interest rate decreases business fixed investment and consumer durable spending, which ultimately affects the aggregate output in a downward direction. This will decrease the equilibrium price level (Mishkin, 1996).

\subsection{Exchange rate channel}

This channel states that a rise in the nominal interest rate increases the real interest rate which attracts foreign investors, thereby increasing foreign exchange reserves (FER). This capital flight appreciates the local currency, which means that in the foreign market the domestic product will be expensive, thereby decreasing demand for domestic products in the foreign market. Consequently, the net export (NX) will start falling and this will affect aggregate demand and then prices in a negative direction.

$$
\mathbf{i} \uparrow \rightarrow \mathbf{i}_{\mathbf{r}} \uparrow \rightarrow \text { Capital inflow } \uparrow \rightarrow \text { FER } \uparrow \rightarrow \text { ER } \downarrow \rightarrow \mathrm{NX} \downarrow \rightarrow \mathrm{Y} \downarrow \rightarrow \mathrm{P} \downarrow
$$

The details of this channel can be found in Mishkin (1996).

\subsection{Cost channel}

According to the cost channel of MTM, when the authority increases the nominal interest rate, this leads to an increase in the cost of working capital. Subsequently, the production cost of the business will rise, and producers will pass on this increase to consumers. In this way the inflation will take an upward direction.

$$
\text { i } \uparrow \rightarrow \text { cost of working capital } \uparrow \rightarrow \text { Cost of Production } \uparrow \rightarrow P \uparrow
$$

\subsection{Assets Price Channel}

This channel explores how monetary policy affects equity prices or stock prices which further affect investment and consumption. There are two channels linking stock prices with investment and consumption: (i) Tobin's q theory of investment; and (ii) effect of wealth on consumption. When central banks increase interest rates which makes bonds attractive, stock prices take a downward direction. It is known that a fall in stock prices will lead to a decrease in Tobin's $\mathrm{q}^{2}$ which will reduce investment spending and finally affect aggregate demand and prices in a negative direction.

$$
\mathbf{i} \uparrow \rightarrow \mathbf{S P} \downarrow \rightarrow \mathbf{q} \downarrow \rightarrow \mathbf{I} \downarrow \rightarrow \mathbf{Y} \downarrow \mathbf{P} \downarrow
$$

Other than Tobin's q investment channel there is an alternative channel called the wealth effect channel of the monetary transmission mechanism. Modigliani (1971) argues that stock is the main component of wealth. A fall in stock value leads to a fall in wealth which decreases the current consumption and finally negatively affects aggregate demand and prices.

$$
\text { i } \uparrow \rightarrow \mathrm{SP} \downarrow \rightarrow \text { wealth } \downarrow \rightarrow \text { consumption } \downarrow \rightarrow \mathrm{Y} \downarrow \rightarrow \mathrm{P} \downarrow
$$




\subsection{Credit channel}

The credit channel of MTM can occur through two sub-channels; bank lending conduits and balance sheet conduits (Mishkin, 1996). The bank lending channel affects prices and when the central bank injects money, it enhances bank reserves and deposits which will, in return, increase the number of bank loans available. This will boost investment and spending to rise and affect prices in an upward direction. Monetary policy can affect a firm's balance sheet conduits in different ways which are discussed in detail by Hernando (1998).

\subsection{Expectation channel}

According to the expectation channel, with decrease in the interest rate, increase the money supply which can raise the expected price $\left(P^{e}\right)$ and hence expected inflation $\left(\pi^{e}\right)$, Mishkin (1996).

$$
\mathbf{i} \downarrow \rightarrow \mathbf{M S} \uparrow \rightarrow A=P^{e} \uparrow \rightarrow \pi^{e} \uparrow
$$

\section{THEORETICAL AND METHODOLOGICAL FRAMEWORK}

The modified PC causal algorithm of GTA provides an effective statistical and mathematical tool to find causality in financial stock markets. Swanson and Granger (1997) for the first time used it in economics to find the causal direction. Swanson and Granger assumed that VAR residuals contain the information about causal ordering, therefore they treated VAR residuals as original variables in PC algorithm to find causality. However, there are some logical flaws and weak points attached to VAR residuals due to which the causality results cannot be fully relied.

Consider a VAR model:

$$
\begin{aligned}
& y_{t}=\alpha_{1}+\beta_{1} x_{t-1}+\beta_{2} y_{t-1}+\varepsilon_{1 t} \\
& x_{t}=\alpha_{2}+\beta_{3} y_{t-1}+\beta_{4} x_{t-1}+\varepsilon_{2 t}
\end{aligned}
$$

After estimating the VAR model, the residuals series extracted from both equations (1) and (2) contain only current information of $x_{t}$ and $y_{t}$, while the effects of past values $x_{t-i}$ and $y_{t-i}$ are removed. Thus, VAR residuals only contain contemporaneous information about the causal feedback from $x$ to $y$ and vice versa. Therefore, this study modifies the existing PC algorithm by replacing VAR residuals with Rehman and Malik (2014) test residuals modified $\mathrm{R}$ recursive residuals and employed it in the current study. These residuals series can eliminate the non-stationarity without removing the effect of cross variable feedback, and treated as original variables in the PC causal algorithm to find the causal determinants of inflation exampling Pakistan as a case study.

Before discussing the novel and modified PC algorithm, it is important to explain and visualize the basic terms and terminologies used in GTA. The graph constructed under GTA contains $N$ nodes; represent variables and $E$ edges; represent association between a pair of nodes. The link between pair of variables without arrowheads are called undirected edges $(\mathrm{A}-\mathrm{B})$, while the link between two variables through a straight-line having arrowhead is 
called a directed edge $(\mathrm{A} \rightarrow \mathrm{B})$ which show us the direction of causality. It is also important to discuss that graph showing only the nodes and strip away all arrowheads from the edges is called skeleton. The direction of causality between pair of variables depend on unshielded collider, and screen-off which is explained in steps involved in modified PC algorithm.

Modified PC algorithm has five steps to determine the causal ordering (Fazal et al., 2021). From step 1 to step 3, it learns from the data information and make a skeleton graph, while in the last two steps it orients the arrows head to construct the final causal graph.

- In step first, the algorithm develops the skeleton graph in which all nodes are linked through undirected links (links without arrowhead).

- In step second, the algorithm starts testing the unconditional correlation between any two nodes and remove the insignificant links from the graph.

- In step third, the algorithm then tests the correlation between every two nodes conditional on a third node, and if the conditional correlation between each pair of nodes are insignificant then again remove the connection between the pair of variables. The first three steps are visualized in the (Figure no. 1).

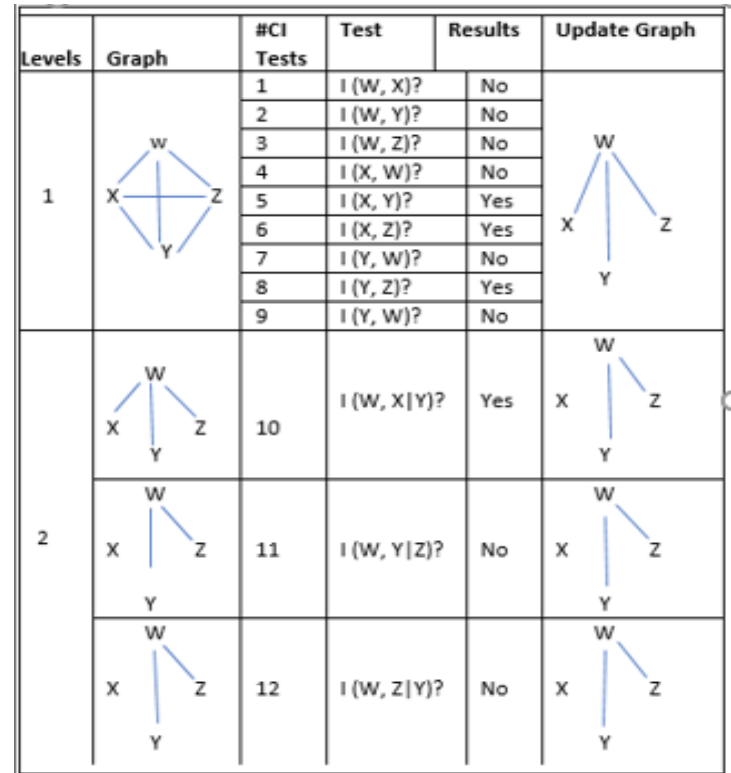

Figure no. 1 - PC Algorithm Learning the Skeleton

- In step fourth, if two nodes are correlated conditional on the third node as discussed in step third, arrows from the two nodes are oriented toward the third node and is called unshielded collider. To explain the term unshielded collider, we have Figure no. 2 which does not show any direct relationship between node $A$ and $\mathrm{B}$ which mean that these two nodes are unconditionally uncorrelated, but conditionally correlated on node $D$ (Fazal et al., 2020 and Hoover, 2005, 2020).

- In the fifth and last step, arrows are oriented based on screening relationship. If two nodes $A$ and $B$ are not directly connected but are connected through a third node $C$ i.e. $A \rightarrow C$ -- $B$. This show that the link from $A$ to $C$ (third node) is directed while the link between nodes 
$C$ and $B$ is undirected. Therefore, the final resultant graph will orient the second link as $A \rightarrow C \rightarrow B$, because orienting the arrow-head toward $C$ indicate unshielded collider which is already revealed in step 4 . Thus, the intervening node or variable is a screen and not an unshielded collider, so the arrow cannot point toward node $C$.

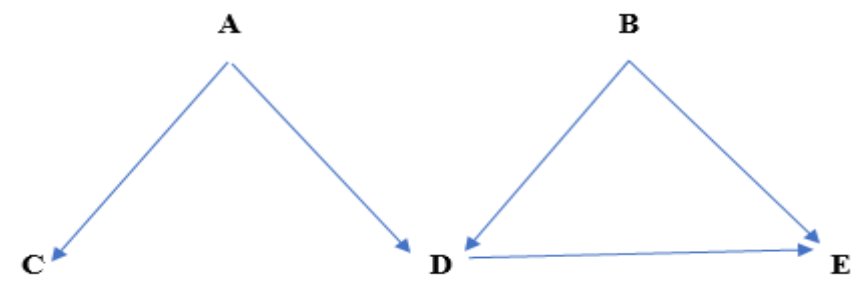

Figure no. 2 - Directed graph

In application Fisher's z statistics are used to test whether the conditional correlations are significantly different from zero.

\section{RESULTS AND DISCUSSION}

This study used quarterly data series i.e. inflation rate, exchange rate, money supply, global oil prices, domestic credit, gross domestic product, unit value of export and import, output gap and interest rate of Pakistan from the period 1990 to 2018 for revealing the causal nexus between monetary policy and inflation exampling Pakistan. The data has been collected from different sources i.e. State Bank of Pakistan (SBP) and International Financial Statistics (IFS). In order to proceed the analysis, we have to check the stationarity of all variables by applying the unit root test known as HEGY test. The data we use in this study is quarterly so HEGY test performs better than ADF. The results show that all the series are first difference stationary at a $5 \%$ significance level.

Table no. 1 - Unit Root Test (HEGY)

\begin{tabular}{|c|c|c|c|c|c|c|c|}
\hline \multirow{2}{*}{\begin{tabular}{l}
\multicolumn{1}{c}{ Variables } \\
Exchange \\
Rate
\end{tabular}} & \multicolumn{3}{|c|}{ At level } & \multirow[t]{2}{*}{ Variables } & \multicolumn{3}{|c|}{ At level } \\
\hline & & t-HEGY & $\begin{array}{l}\text { Critical } \\
\text { value }\end{array}$ & & & t-HEGY & $\begin{array}{l}\text { Critical } \\
\text { value }\end{array}$ \\
\hline & $\pi_{1}$ & -2.75 & -1.99 & \multirow{2}{*}{$\begin{array}{l}\text { Unit Value of } \\
\text { Export }\end{array}$} & $\pi_{1}$ & -3.86 & -2.84 \\
\hline & $\pi_{2}$ & -5.58 & -1.93 & & $\pi_{2}$ & -4.24 & -1.91 \\
\hline \multirow[t]{2}{*}{ Inflation } & $\pi_{1}$ & -1.71 & -1.94 & \multirow{2}{*}{$\begin{array}{l}\text { Unit Value of } \\
\text { Import }\end{array}$} & $\pi_{1}$ & -1.63 & -2.84 \\
\hline & $\pi_{2}$ & -7.94 & -2.83 & & $\pi_{2}$ & -5.55 & -1.91 \\
\hline \multirow{2}{*}{$\begin{array}{l}\text { Money } \\
\text { Supply }\end{array}$} & $\pi_{1}$ & -2.19 & -1.93 & \multirow{2}{*}{$\begin{array}{l}\text { Gross Domestic } \\
\text { Product }\end{array}$} & $\pi_{1}$ & -3.21 & -1.93 \\
\hline & $\pi_{2}$ & -4.85 & -1.91 & & $\pi_{2}$ & -2.11 & -2.65 \\
\hline \multirow{2}{*}{$\begin{array}{l}\text { Oil } \\
\text { Prices }\end{array}$} & $\pi_{1}$ & -2.23 & -2.65 & \multirow{2}{*}{$\begin{array}{l}\text { Interest } \\
\text { Rate }\end{array}$} & $\pi_{1}$ & -2.15 & -1.99 \\
\hline & $\pi_{2}$ & -6.94 & -2.83 & & $\pi_{2}$ & -3.44 & -1.93 \\
\hline \multirow{2}{*}{$\begin{array}{l}\text { Domestic } \\
\text { Credit }\end{array}$} & $\pi_{1}$ & -2.21 & -1.93 & \multirow{2}{*}{$\begin{array}{l}\text { Output } \\
\text { Gap }\end{array}$} & $\pi_{1}$ & -2.63 & -2.65 \\
\hline & $\pi_{2}$ & -3.74 & -2.65 & & $\pi_{2}$ & -3.48 & -2.83 \\
\hline
\end{tabular}

Note: Inflation $(I N F)=$ Inflation, which is calculated by taking the growth rate of CPI. Interest rate $=$ Discount rate. Money Supply = M2. Output gap = Difference between Actual GDP - Potential GDP. 
To test the hypothesis of unit root at zero frequency, t-HEGY values are calculated and compared with critical values. Estimated t-values for variables have been found stationary and significant at a 5\% significance level. On the other hand, we tested the hypothesis of unit root of biannual frequency. The estimated t-values of $\pi_{2}$ for all variables indicate that the hypothesis of unit root at biannual frequency has been rejected in case of all variables.

\subsection{Modified PC algorithm results}

We applied modified PC algorithm of GTA to determine the significant causal directions between monetary policy and inflation by talking both monetary and non-monetary channels as discussed earlier. Modified PC algorithm treat modified R residuals as original variables in TETRAD 4.9.1 software and the results are displayed in Figure no. 3 as under.

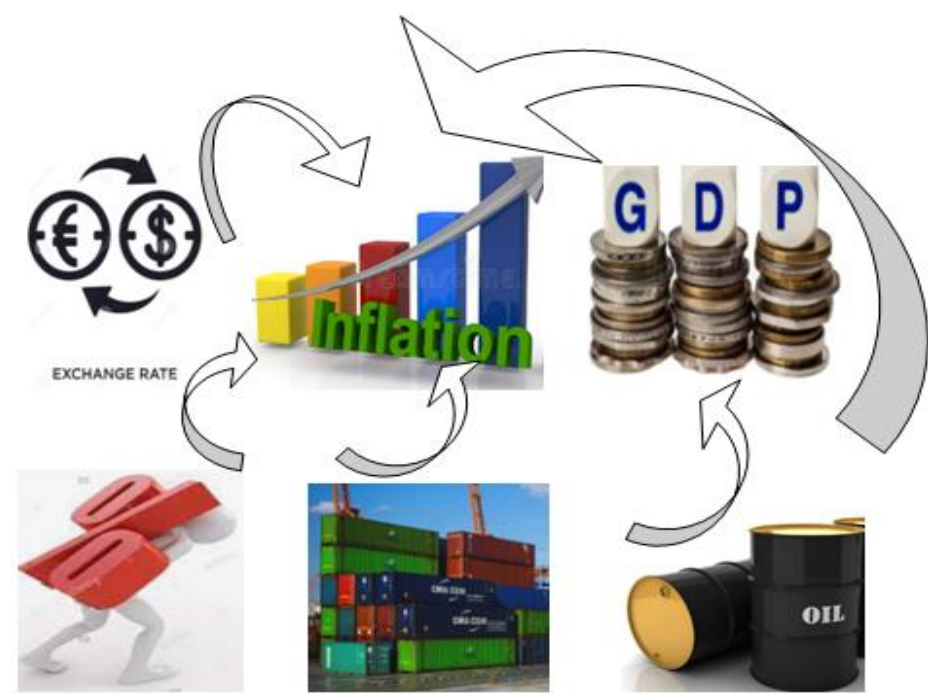

Figure no. 3 - Modified PC algorithm using modified R residuals

The study applied modified PC algorithm and the results indicate that in case of Pakistan the causality running from exchange rate to inflation; the result is in line with the study of Parker (2014) mentioned that the pass-through from exchange rate to inflation is modest and pass-through from exchange rate to import prices is high and quick. This is not surprising because import prices largely reflect the domestic-currency cost of the goods from the foreign supplier, which can be expected to vary in line with the exchange rate. The results also indicate that no causality running from money supply to inflation. According to the Werner Quantity theory of credit, the banks can create money and inflation can have a relationship with the money created by banks. The money that is managed by the central bank is only a small part of the total money and there is no good approximation of total money. Therefore, many monetary models found an insignificant coefficient of the money supply. Modern Monetary Theory also explains that if the money supply is used in the new economic activities, it will not create inflation. This finding is compatible with the work of Asari et al. (2011) that money supply is not a significant element that triggers up the price level. Saini (1982) empirically found that the money stock growth is not the primary source of inflation. 
The results also indicate that causality running from interest rate to inflation. The earlier findings of , Mehwish et al. (2017), Onanuga and Onanuga (2014), Khumalo et al. (2017), Asgharpur et al. (2007) that interest rate is a significant determinant of inflation is not rejected. This indicates the effectiveness of monetary policy. If the interest rate affects prices in a negative direction then monetary policy will be productive, in case of positive direction monetary policy will be counterproductive. We have found the significant determinants of inflation and interest rate is among there. A very important question is unanswered that in which direction interest rate affects inflation? The algorithm is not capable of informing about the dimension of the relationship. To solve the issue, we have estimated the following autoregressive distributed lag model (ARDL) model by including all the significant determinants found through the graphtheoretic approach. The results are given in Table no. 2.

\subsection{ARDL Model}

We have constructed the following ARDL model (1), the estimated results are provided in Table no. 2.

$$
\begin{gathered}
\text { Inf }=\alpha+\beta_{1} i n f_{t-1}+\beta_{2} E R+\beta_{1} E R_{t-1}+\beta_{1} U V E+\beta_{1} U V E_{t-1}+\beta_{1} I R+\beta_{1} I R_{t-1} \\
+\beta_{1} O G+\beta_{1} O G_{t-1}+\mu \ldots(1)
\end{gathered}
$$

\begin{tabular}{|c|c|c|c|}
\hline Variables & Coefficient & SE & t-value \\
\hline Inflation $\mathrm{t}-1$ & 0.988 & 0.0125 & 78.780 \\
\hline Constant & 0.0902 & 0.0330 & 2.729 \\
\hline Exchange rate & 0.0015 & 0.0003 & 5.033 \\
\hline Exchange rate $t_{-1}$ & -0.0010 & 0.0003 & -3.166 \\
\hline Unit value of export & 0.0011 & 0.0004 & 2.700 \\
\hline Unit value of export $t-1$ & -0.0012 & 0.0004 & -2.975 \\
\hline Interest rate & 0.0042 & 0.0010 & 4.130 \\
\hline Interest rate $\mathrm{t}-1$ & -0.0035 & 0.0010 & -3.460 \\
\hline Output Gap & -0.0003 & 0.0001 & -2.500 \\
\hline Output Gap $_{\mathrm{t}-1}$ & 0.0002 & 0.0001 & 1.800 \\
\hline
\end{tabular}

Table no. 2 - ARDL Estimated Results

The ARDL model has many advantages; in particular, it can be used to find an appropriate model when there are multiple theories. After calculating ARDL, we find the static long-run solution (SLRS) through the procedure given in Charemza and Deadman (1997).

Table no. 3 - Static Long-Run Equation

\begin{tabular}{lrrr}
\hline Variables & Coefficient & SE & t-value \\
\hline Constant & 7.510 & 0.201 & 37.3 \\
Exchange rate & 0.041 & 0.004 & 10.2 \\
Unit value of export & -0.008 & 0.003 & -2.66 \\
Interest rate & 0.058 & 0.030 & 1.93 \\
Output Gap & -0.008 & 0.007 & -1.14 \\
\hline
\end{tabular}


After estimating the static long-run equation, we found the coefficient of interest rate positive which indicate that increasing the interest rate the inflation is going up, and causality run from interest rate to inflation. Rehman (2015) is his study Revival of Legacy of Tooke and Gibson: Further Evidence and Implications for Monetary Policy finds the same results that the correlation between inflation and interest rate is positive in case of Pakistan. If the correlation between interest rate and inflation is positive then using interest rate to control inflation would be counterproductive.

\section{CONCLUSION AND RECOMMENDATIONS}

There has been a long discussion and debate on the validity and functioning of monetary policy. Theoretical literature lists both monetary and non-monetary channels linking interest rate and inflation. However, most of the existing studies are focused on single equation model ignoring other parallel channels. This paper highlighted the shortcomings attached to the previous studies; and developed novel modified Peter and Clark (PC) by taking all the monetary and non-monetary channels to determine the causal nexus between monetary policy and inflation. The classical assumption is that increase in interest rate will decrease inflation but there are many evidences showing high interest rate associated with high inflation. So, the theoretical literature and data-based evidences differ remarkably. The issue is that the theoretical literature exhibits that there are many causal paths that connect the monetary policy actions to monetary policy targets but previous studies did not take into account all these paths. Therefore, it becomes important to list all popular theoretical channels and discuss their chain of causality. The current study employed a Graph-theoretic approach and explored significant determinants of inflation. We find that contrary to the assumption of mainstream monetary theory, the money supply is not a significant determinant of inflation, but the interest rate is a determinant. To find the direction of relationship between interest rate and inflation, we calculate a static long-run solution. We find that interest rate and inflation are positively associated, which implies the monetary policy to be counterproductive in case of Pakistan. It is important to mention that; monetary policy will be counterproductive if cost side effects of monetary tightening prevail. High energy prices may increase the cost of production by reducing aggregate supply in the economy. If tight monetary policy is used to reduce this cost push inflation, the cost side effect will add to cost side effects of monetary tightening and will become dominant. In this case, the monetary policy will be counterproductive. This is support to the popular Gibson Paradox (Gibson, 1923) and Price Puzzle (Sims, 1992). The findings imply there is a need of serious rethinking about the current monetary policy regime. The cost channels should be made part of monetary policy modeling and before the conduct of monetary policy, there is a need to make sure that it actually works.

Furthermore, the present research focuses only on the observable variables of monetary transmission mechanism and applied PC algorithm to find the causal relationship between interest rate and inflation. The PC algorithm does not handle the latent variable and assume that there is no latent variable. However, one can extend the current study by taking both observable and latent variables to validate and improve these results using the recently developed causality algorithm i.e. tsFCI and SVAR-FCI. 


\section{ORCID}

Md Shabbir Alam (D) https://orcid.org/0000-0002-5001-4553

Naushad Alam (D) https://orcid.org/0000-000-2557-9157

\section{References}

Angelina, S., and Nugraha, N. M., 2020. Effects of Monetary Policy on Inflation and National Economy Based on Analysis of Bank Indonesia Annual Report. Technium Social Sciences Journal, 10(1), 423-435.

Asari, F. F. A. H., Baharuddin, N. S., Jusoh, N., Mohamad, Z., Shamsudin, N., and Jusoff, K., 2011. A vector error correction model (VECM) approach in explaining the relationship between interest rate and inflation towards exchange rate volatility in Malaysia. World Applied Sciences Journal, 12(3), 49-56.

Asgharpur, H., Kohnehshahri, L. A., and Karami, A., 2007. The relationships between interest rates and inflation changes: An analysis of long-term interest rate dynamics in developing countries. Paper presented at the International Economic Conference on Trade and Industry (IECTI), Bayview Hotel Georgetown, Penang.

Barth, M. J., and Ramey, V. A., 2001. The cost channel of monetary transmission. NBER Macroeconomics Annual, 16, 199-240. http://dx.doi.org/10.1086/654443

Charemza, W. W., and Deadman, D. F., 1997. New directions in econometric practice: Books.

Demiralp, S., and Hoover, K. D., 2003. Searching for the causal structure of a vector autoregression. Oxford Bulletin of Economics and Statistics, 65, 745-767. http://dx.doi.org/10.1046/j.03059049.2003.00087.x

Fazal, R., Rehman, A., and Alam, A., 2020. Tracing Causality and Co-Movement Between Pakistani and The Leading Foreign Stock Markets: A Graph Theoretic Approach. International Review of Management and Business Research, 9(4).

Fazal, R., Rehman, S. A. U., Rehman, A. U., Bhatti, M. I., and Hussain, A., 2021. Energy-environmenteconomy causal nexus in Pakistan: A graph theoretic approach. Energy, 214, 118934. http://dx.doi.org/10.1016/j.energy.2020.118934

Gibson, A. H., 1923. The Future Course of High Class Investment Values. Banker's Magazine, 115(January), 15-34.

Hernando, I., 1998. The credit channel in the transmission of monetary policy: the case of Spain. Topics in Monetary Policy Modelling, 257-275. https://www.bis.org/publ/confp06j.pdf.

Hoover, K. D., 2005. Automatic inference of the contemporaneous causal order of a system of equations. Econometric Theory, 21(1), 69-77. http://dx.doi.org/10.1017/S026646660505005X

Hoover, K. D., 2020. The Discovery of Long-Run Causal Order: A Preliminary Investigation. Econometrics, 8(3), 31. http://dx.doi.org/10.3390/econometrics8030031

$\mathrm{Hu}, \mathrm{Q}$., and Quan, J. J., 2005. Evaluating the impact of IT investments on productivity: A causal analysis at industry level. International Journal of Information Management, 25(1), 39-53. http://dx.doi.org/10.1016/j.ijinfomgt.2004.10.006

Khumalo, L. C., Mutambara, E., and Assensoh-Kodua, A., 2017. Relationship between inflation and interest rates in Swaziland revisited. Banks and Bank Systems, 12(4), 218-226. http://dx.doi.org/10.21511/bbs.12(4-1).2017.10

Kumar, V., Acharya, S., and Ho, L. T., 2020. Does Monetary Policy Influence the Profitability of Banks in New Zealand? International Journal of Financial Studies, 8(2), 35. http://dx.doi.org/10.3390/ijfs8020035

Ma, X., Yang, R., Zou, D., and Liu, R., 2020. Measuring extreme risk of sustainable financial system using GJR-GARCH model trading data-based. International Journal of Information Management, 50, 526-537. http://dx.doi.org/10.1016/j.ijinfomgt.2018.12.013 
McCallum, B. T., 1981. Price level determinacy with an interest rate policy rule and rational expectations. Journal of Monetary Economics, 8(3), 319-329.

Mehwish, M. N., U., S., and K., S. U., 2017. Correlation and Causality between Inflation and Selected Macroeconomic Variables: Empirical Evidence from Pakistan. iBusiness, 9, 149-166.

Mishkin, F. S., 1996. The channels of monetary transmission: lessons for monetary policy (Vol. w5464): National Bureau of Economic Research. http://dx.doi.org/10.3386/w5464

Modigliani, F., 1971. Monetary Policy and Consumption: Linkages via Interest Rate and Wealth Effects in the FMP Model, Consumer Spending and Monetary Policy: The Linkages. Consumer spending and monetary policy: the linkages. Proceedings of a Monetary Conference, 9-28.

Onanuga, A., and Onanuga, O., 2014. The Impact of Interest Rate Channel of Monetary Policy on Output and Prices in Nigeria: An Unrestricted VAR Approach. Journal of African Macroeconomic Review, 4(1), 286-294.

Osterholm, P., and Berger, M. H., 2008. Does money growth granger-cause inflation in the euro area? Evidence from out-of-sample forecasts using Bayesian VARs. IMF Working Papers, 2008(53). http://dx.doi.org/10.5089/9781451869156.001

Parker, M., 2014. Exchange rate movements and consumer prices: Some perspectives. Reserve Bank of New Zealand Bulletin, 77(1), 31-41.

Rashid, A., and Husain, F., 2013. Capital inflows, inflation, and the exchange rate volatility: An investigation for linear and nonlinear causal linkages. Pakistan Development Review, 52, 183-206. http://dx.doi.org/10.30541/v52i3pp.183-206

Rehman, A. U., 2015. Revival of legacy of Tooke and Gibson: Implications for monetary policy. Journal of Central Banking Theory and Practice, 4(2), 37-58. http://dx.doi.org/10.1515/jcbtp-2015-0008

Rehman, A. U., and Malik, M. I., 2014. The modified R a robust measure of association for time series. Electronic Journal of Applied Statistical Analysis, 7(1), 1-13.

Saini, K. G., 1982. The monetarist explanation: The experience of six Asian countries. World Development, 10(10), 871-884. http://dx.doi.org/10.1016/0305-750X(82)90062-6

Sims, C. A., 1992. Interpreting the macroeconomic time series facts: The effects of monetary policy. European Economic Review, 36(5), 975-1000. http://dx.doi.org/10.1016/0014-2921(92)90041-T

Swanson, N. R., and Granger, C. W., 1997. Impulse response functions based on a causal approach to residual orthogonalization in vector autoregressions. Journal of the American Statistical Association, 92(437), 357-367. http://dx.doi.org/10.1080/01621459.1997.10473634

Taylor, J. B., 1995. The monetary transmission mechanism: An empirical framework. The Journal of Economic Perspectives, 9(4), 11-26. http://dx.doi.org/10.1257/jep.9.4.11

\footnotetext{
Notes

${ }^{1}$ Money market.

${ }^{2}$ According to Tobin's q theory, monetary policy affects the economy through the valuation of stock prices (Mishkin, 1996). Tobin presented q as the market value of a business divided by the replacement cost of capital. If $q$ is high, new capital is cheap relative to the market value of a business firm, thereby increasing investment expenditure.
}

\section{Copyright}

This article is an open access article distributed under the terms and conditions of the Creative Commons Attribution-NonCommercial-NoDerivatives 4.0 International License. 